\title{
Risk factors for cardiovascular disease in the Ga-Rankuwa community
}

\author{
YQ Li, M Tech Nursing \\ Department of Nursing Science, Tshwane University of Technology \\ SCD Wright, D Tech Nursing \\ Senior lecturer, Tshwane University of Technology
}

Correspondence address:

SCD Wright

Department of Nursing Science

Tshwane University of Technology

Private bag $x 680$

Pretoria, 0001

Tel : (012) 382-5470

Fax : (012) 382-5033

E-mail : wrightscd@tut.ac.za

\section{Abstract: Curationis 30(4): -79-87}

Cardiovascular disease is the most common and yet one of the most preventable causes of death in the world. Rapid urbanization in South Africa is accompanied by rapid changes in lifestyle and environmental exposure that increase the burden of chronic cardiovascular diseases. Risk factors, modifiable or nonmodifiable, exist that increases a person's chances of developing cardiovascular disease. Though some knowledge is available about the prevalence of the risk factors in South Africa, no information is available regarding the community of Ga-Rankuwa. The purpose of the study was therefore to investigate the prevalence of risk factors for cardiovascular disease amongst the working-age people (18-40 years) in Ga-Rankuwa community. A quantitative survey was done and the sample was selected from zone 1,2, 4, and 16 of Ga-Rankuwa from July 2005 to October 2005 . The sampling method was census sampling $(n=604)$. The data-gathering was self-report using a structured questionnaire as well as physical measurement. Data were analysed using descriptive statistics. The results indicated that risk factors, specifically obesity, physical inactivity and hypertension, were very prevalent in Ga-Rankuwa community. Different distributions of risk factors exist in the various sex and age groups. This finding again emphasises the importance of not developing health interventions with a single focus, for example hypertension or obesity. The risk factors are interwoven and affect each other. It is important to initiate a comprehensive health project to lower the risk factors of cardiovascular disease in the Ga-Rankuwa community.

\section{Background, rationale and research problem}

Cardiovascular disease is the most common and yet one of the most preventable causes of death in the world. The impact of urbanisation on the emergence of chronic diseases risk factors in sub-Saharan African countries is one of the major influences on the population, which is undergoing unprecedented levels of migration from century-old traditional lifestyles in rural areas to the large peri-urban settlements of cities in the region (Steyn, 2006:2). Urbanisation has an effect on almost all the aspects of the migrants' lifestyle that contributes to in- creasing levels of chronic diseases risk (Steyn, 2006:2).

Over the last decade, the epidemiological challenges have increased in South Africa. HIV/AIDS has now ballooned to become the major cause of death, while chronic diseases, especially cardiovascular disease, diabetes have steadily emerged as major threats to health across the spectrum of South Africa's diverse racial and social class groupings (Steyn, 2006:2).

In the early nineties, Seedat et al. (1992:251) reported that cardiovascular disease was still uncommon in the black population of South Africa with a prevalence of $2.4 \%$. It was also reported that 
black people have very low mortality rates for coronary heart disease, but relatively high mortality rates for cerebrovascular accidents and other forms of heart disease (Medical Research Council, 1987). This is supported by research done for the Southern Africa Stroke Prevention Initiative $(n=68525)$, indicating a stroke incidence of 300 per 100000 people. Of the stroke survivors, 200 per 100 000 people $(66 \%)$ were disabled (Thorogood, 2004). The research shows that rural South Africa faces a stroke crisis similar to affluent Western countries. Epidemiologic studies (Smeltzer \& Bare, 1996:639) state that there are conditions that precede or accompany the onset of cardiovascular disease. These conditions are called risk factors because the presence of one or more is believed to increase one's risk of developing a cardiovascular disease. These risk factors may be modifiable or nonmodifiable risk factors. Nonmodifiable factors are the consequence of genetics over which an individual has no control, and includes a positive family history, increasing age, or gender. Modifiable factors are hypertension, diabetes mellitus, physical inactivity, obesity, cigarette smoking; stress and behaviour patterns, and personality traits such as being highly competitive, aggressive or ambitious (Smeltzer \& Bare, 1996:639). For this study, modifiable factors such as hypertension, diabetes mellitus, physical inactivity, obesity, cigarette smoking, and unhealthy diet were investigated in a community setting.

Current knowledge regarding the prevalence of the risk factors is as follows:

•

The prevalence of hypertension in South Africa among black men has risen to $20.2 \%$, and among black women, the prevalence is $23.5 \%$ (Department of Health, 2002).

- In urbanised black populations in South Africa, surveys estimate the prevalence of diabetes at $8 \%$ in people over 30 years of age (Omar et al., 1993:642; Levitt et al., 1993:601).

- $\quad$ Physical inactivity has been suggested as a factor contributing to an increased risk of cardiovascular disease. Heim, Holcomb and Loughin (2000: 1352) showed that increased physical activity is associated with a lower waist- hip ratio and a higher HDLcholeserol level in women, and that physical activity was inversely associated with body mass index and percentage body fat. The problem in this regard is highlighted by a survey reported by the Department of Health (2002). In black

populations in South Africa, the survey showed that the waisthip ratio above cut-off in men is $6.5 \%$, and for women $33.3 \%$.

- Obesity is also important in the formation of risk factors for cardiovascular disease. The prevalence of obesity in South Africa among black women in the North West province has risen to 28,6\% (Kruger, Venter \& Vorster, 2001:733), whereas among women in Cape Town the figure is $34,4 \%$ (Steyn et al., 1998:36).

\section{Problem statement and purpose of the study}

Cardiovascular disease has become one of the top health priorities today. From participant observation in the $\mathrm{Ga}$ Rankuwa community, obesity and physical inactivity is common. From previous research done in Ga-Rankuwa, the prevalence of both obesity and hypertension were higher than the national level (Wright \& Ramukumba, 2006). The waisthip ratio indicated that $20 \%$ of the men and $49.7 \%$ of the women were above the cut-off point. High blood glucose values were demonstrated for $21.6 \%$ of the combined group. Physical activity was also shown to be inadequate. However, the study sample was small $(n=218)$ and therefore a decision was taken to investigate the prevalence of these risk factors in Ga-Rankuwa in a larger sample. The purpose of the study was therefore to investigate the prevalence of risk factors for cardiovascular disease amongst the working-age people (18-40 years) in Ga-Rankuwa community.

\section{Research methods and design}

\section{Context}

The geographical location for the study is Ga-Rankuwa, a township $35 \mathrm{~km}$ north of Pretoria. According to Stats Council Census (SA, 2001), the estimated population of the township is 83912 people, but growing at a rapid rate. There are various ethnic groups but the majority are African-Black (99.6\% of population), with $74 \%$ speaking Setswana.

\section{Design}

The design was a quantitative survey. According to Burns and Grove (2001:28), quantitative research is conducted to describe and examine relationships and determine causality among variables.

\section{Population}

The target population for the study was the working-age people from 18 to 40 years, living in Ga-Rankuwa community. The accessible population was selected from zone 1 , zone 2 , zone 4 , and zone 16 of Ga-Rankuwa during July 2005 to October 2005. The four zones were in the western region of Ga-Rankuwa community and were chosen because of their close proximity to each other and to improve the feasibility of the study. As a door-to-door survey was done, the sampling method was a census sample. The sample size included in the study was 604 respondents.

\section{Data gathering}

The data gathering method was a structured interview using a structured questionnaire as a data gathering instrument (Burns \& Grove, 2001:421). The risks for cardiovascular disease questionnaire had been designed to measure independent and dependent variables which were based on the cardiovascular survey methods proposed by Luepker et al., (2004:95). The questionnaire was pretested in a similar area in Tshwane. The aim of the pre-testing was to eliminate unforeseen problems that could arise, and to test the feasibility of the data-gathering process. Five questionnaires were used in the pre-test and no problems could be discerned from the respondents who completed the questionnaires.

For each participant, the researcher and two fieldworkers conducted a 40-60 minute home interview, collecting demographic and lifestyle data, and information regarding physical inactivity and dietary habits. Informed consent was obtained before the data were gathered. The two fieldworkers were from the community and could speak the local languages. The researcher did all the measurements to prevent variability in the measurement. The following data were gathered:

- $\quad$ Structured questionnaire. In 
the questionnaire, the following independent variables were investigated: age, gender, level of education, occupation and type of housing. Questions were also asked about the following dependent variables: diagnosed medical conditions, smoking history, and alcohol consumption.

Physical inactivity. The physical activity was measured in terms of time walked or cycled per day, work hours and leisure time. Physical inactivity was calculated based on a composite physical activity index (Kruger, Venter \& Steyn, 2000: 55).

- Dietary habits. According to Luepker et al. (2004), 24-hour recordings of a large group of respondents are an effective way to measure the average dietary consumption of the group.

- Anthropometric measurements. Respondents wearing only light indoor clothing were weighed on a Seca beam scale, and their height measured on the samescale. In male respondents in the upright position, the circumference of the waist was measured with a fibreglass tape measure to the nearest 0,5 centimetre at the level of the umbilicus at the expiration, while the respondents were breathing normally. In female respondents, the waist circumference was measured in the same way but at the narrowest point between the rib cage and the iliac crest. The hip circumference was measured at the level of the greater trochanter. Both mesurements were taken in the horizontal plane (Luepker et al., 2004).

Blood pressure measurements.

Blood pressure was measured at the respondents' homes where the noise level was low All measurements were made using a previously calibrated mercury sphygmomanometer. The first and fifth Korotkoff sounds were used for systolic and diastolic pressures. The 9centimetre cuff was used for respondents with a mid-upper arm circumference of 22-36 cen timetres. The 12-centimetre cuff was used when the midupper arm circumference exceeded 36 centimetres. Two measurements were taken for each subject over a period of about 15 minutes, and the second was recorded.

\section{Data analysis}

The data were analysed with descriptive statistics. During data analysis, the percentage distribution, mean, and the standard deviation of the variables described the prevalence of risk factors for cardiovascular disease in the study sample of the Ga-Rankuwa community.

\section{Ethical considerations}

The ethical standards proposed in the position paper of the Democratic Nursing Organization of South Africa (DENOSA, 1991:1-5) for nursing researchers were followed in this research.

Consent to conduct this research study was obtained from the Faculty Research Committee and Ethics Committee of Tshwane University of Technology. Sufficient information about the study was given to all subjects in a language they were comfortable with. The information leaflet and the letter of consent were in English. All the participants were requested to complete the consent form before they participated in the research.

All information obtained in connection with the study was kept strictly confidential. The study had to use the participants' names, addresses and contact details because the participants were visited at home. To maintain confidentiality, the names and addresses of the participants were recorded on a front sheet that could be removed from the questionnaire after completion and the serial number of the participant had been entered on the next sheet of the questionnaire. The rights and property of the participants were protected at all times. Privacy implies that an individual may think and behave without the possibility of such private behaviour or thoughts being used to embarrass the person in question. The privacy of participants in the research study was ensured and no privately divulged behaviour or thoughts were included to humiliate the participants. The respondents were visited at home to complete the questionnaire, and the physical examination was done in privacy. No known or expected harm was implied or caused to the participants in the study.

\section{Validity and reliability}

Validity and reliability were ensured by taking the following into consideration (Burns \& Grove, 1999:477):

Instrument. A questionnaire is a self-report instrument (Brink, 2002:179) with the advantage that it can be given to a large number of people. The questionnaire, which served as the measuring instrument, was constructed from the available literature based on cardiovascular survey methods (Luepker et al., 2004:96). The questionnaire was pre-tested before gathering data.

- $\quad$ Structured interviews. Structured interviews include strategies that provide increasing control by the researcher over the content of the interview. Structured interviews are conducted face to face. The fieldworkers acted as interpreters and answered any questions the respondents may have had in their own language.

- $\quad$ Physical measurements. Blood pressure measurements were made using a previously calibrated mercury sphygmomanometer. The researcher, using standard methods and calibrated equipment, did the anthropometric measurements. Only one person measured the blood pressure and took the anthropometric measurements to prevent interpersonal variability. Initial and periodic standardisation of techniques was done. Each participant's weight, height, hip circumference, waist circumference, $2^{\text {nd }}$ systolic blood pressure, $2^{\text {nd }}$ diastolic blood pressure, and $2^{\text {nd }}$ heart rate were determined and compared with cut-off points obtained from a reference population.

- $\quad$ Language. The language used in the questionnaire was English. Two fieldworkers from the Ga-Rankuwa community were employed to prevent misunderstanding due to language problems. The fieldworkers 
TABLE 1: Distribution of respondents in categories of physical activity $(n=604)$

\begin{tabular}{|c|c|c|c|c|c|}
\hline Physical activity category & Level of physical activity & $\frac{\text { Mak }}{\mathrm{n}}$ & $\%$ & $\frac{\text { Female }}{n}$ & $\%$ \\
\hline \multirow[t]{2}{*}{ Occupational activity } & Mostly sedentary & 128 & 38.3 & 116 & 43.0 \\
\hline & Mostly standing activities & 206 & 61.7 & 154 & 57.0 \\
\hline \multirow[t]{2}{*}{ Commuting activity } & Commuting & 236 & 70.7 & 205 & 75.9 \\
\hline & Walking/cycling daily & 98 & 29.3 & 65 & 24.1 \\
\hline \multirow[t]{2}{*}{ Leisure-time activity } & Mostly sedentary & 206 & 61.7 & 153 & 56.7 \\
\hline & Mostly standing activities & 128 & 38.3 & 117 & 43.3 \\
\hline
\end{tabular}

Physical
inactivity

Physical inactivity was graded as active, moderately active and inactive, based on a composite physical activity index (Kruger, Venter \& Steyn, 2000:55). The distribution of the respondents in the categories of occupational activity, commuting activity, and leisure-time activity is depicted in Table 1. According to occupational activity, six of every ten males and half of the females were standing most of the time. Six of every

were trained and supervised.

\section{Results: Prevalence of risk factors for cardiovascular disease \\ Demographic profile}

Four age groups were used for the analysis. More men than women (334 versus 270) participated in the study. The 18-24 year old age group had the highest number of respondents for both males $(35 \%)$ and females $(38.9 \%)$. The majority $(86.8 \%)$ of the study sample had a secondary or higher education, and a high unemployment rate was observed.

\section{Clinical details: medical history}

Self-reported medical conditions were limited. Only 11 respondents reported having had a myocardial infarction, and only two reported that they have had a stroke. Four persons reported that they have had rheumatic heart disease, and 49 (8.1\%) reported they were hypertensive. The prevalence of diabetes mellitus was low; only 9 persons reported being diabetic. Hypertension was reported by $8.1 \%$ in the study sample ( 24 male respondents and 25 females).

\section{Smoking status}

Smoking as a risk factor occurred in $35.8 \%$ of males and $8.0 \%$ of females. The percentage of males who were currently smoking was four times higher than the smoking female group. Current male smokers in 18-24 age group constituted the highest percentage (39.3\%), whereas females in 35-40 age group who were current smokers constituted the highest percentage $(12.3 \%)$.

Approximately one out of ten males who were current smokers smoked 10 or more cigarettes per day at the high-risk level, whereas only one female respondent who was a current smoker, smoked 10 or more cigarettes per day at the high-risk level in the study sample (Ignatavicius, Workman \& Mishler, 1999:726). In terms of the period of smoking, $57.0 \%$ of the respondents reported that they have been smoking for more than 5 years.

\section{Alcohol consumption}

Alcohol consumption was graded as heavy in those who reported drinking three or more drinks per day during the week and/or five or more drinks per day during weekends, and as light to moderate in those who reported consuming less quantities of alcohol (Metcalf et al., 1996:21). Alcohol consumption was high in males $(17.7 \%)$ between the ages of 18 to 40 years, while only $3.7 \%$ of the females reporting to be using alcohol heavily.

Among the respondents who consumed alcohol, only $9.0 \%$ had been advised by doctors to reduce their alcohol intake. Half of the respondents were of the opinion that they should cut down on their drinking. One in five of the respondents who consumed alcohol reported that they were addicted to alcohol. ten males and more than half of females were mostly sedentary in their leisure time.

The results of the composite physical activity index score indicate that more than $34.3 \%$ of the males and $43.3 \%$ of the females were classified as inactive. Only $27.3 \%$ of the males and $12.6 \%$ of the females were in the active category.

\section{Dietary intake}

According to Steyn et al. (2001:145), dietary intake can be categorised as energy, protein, total fat, carbohydrate and fibre. In the study sample, maize meal was the staple food. Spinach was the most frequently consumed vegetable, and bananas and apples the most popular fruits. Legumes and chicken were the most commonly eaten protein dishes. Table 2 presents data on the nutrition

TABLE 2: Mean (SD) nutrition intake in the study sample

\begin{tabular}{|c|c|c|}
\hline Nutrition intake & Male & Female \\
\hline Energy $(\mathrm{KJ})$ & 6107 & 6321 \\
\hline Protein $(g)$ & 61.0 & 55.2 \\
\hline Total fat $(\mathrm{g})$ & 28.6 & 25.3 \\
\hline Carbohydrate (g) & 223.5 & 57.9 \\
\hline Fibre (g) & 12.2 & 18.3 \\
\hline
\end{tabular}


TABLE 3: Prevalence of selected risk factors ${ }^{\star}$ for cardiovascular disease

\begin{tabular}{|c|c|c|c|c|}
\hline \multirow[t]{2}{*}{ Group $\operatorname{Pr}$} & \multicolumn{4}{|c|}{ Prevalence of selected risk factors $(\%)$} \\
\hline & $\mathbf{0}$ & $\mathbf{1}$ & 2 & 3-6 \\
\hline \multicolumn{5}{|l|}{ Male } \\
\hline $18-24$ & 12.8 & 29.9 & 37.6 & 19.7 \\
\hline $25-29$ & 15.0 & 28.4 & 35.8 & 20.8 \\
\hline $30-34$ & 3.2 & 27.0 & 23.8 & 46.0 \\
\hline $35-40$ & 5.8 & 23.0 & 20.7 & 50.5 \\
\hline Total & 9.2 & 27.1 & 29.5 & 34.2 \\
\hline \multicolumn{5}{|l|}{ Female } \\
\hline $18-24$ & 11.5 & 38.1 & 24.8 & 25.6 \\
\hline $25-29$ & 10.7 & 23.2 & 44.6 & 21.5 \\
\hline $30-34$ & 3.8 & 36.5 & 23.1 & 36.6 \\
\hline $35-40$ & 1.8 & 21.1 & 33.3 & 43.8 \\
\hline Total & 7.0 & 29.8 & 31.5 & 31.9 \\
\hline Overall total & 8.8 & 28.5 & 30.5 & 32.2 \\
\hline $\begin{array}{l}\text { * The } 6 \text { risk fa } \\
\text { history, a posi } \\
\text { tivity and obe }\end{array}$ & con & $\begin{array}{l}\text { is ar } \\
\text { okin }\end{array}$ & posi & $\begin{array}{l}\text { medica } \\
\text { cal inac }\end{array}$ \\
\hline
\end{tabular}

intake of the study sample. The female group had a higher energy, carbohydrate and fibre intake than the male group. The mean protein and total fat intake was higher in the male group.

\section{Physical measurements}

The values of body mass index (BMI) will be described in terms of normal weight, overweight, obesity and severely obese (Department of Health, 2002):

Normal: $B M I=18-24.9 \mathrm{~kg} / \mathrm{m} 2$

Overweight: $\mathrm{BMI}=25-29.9 \mathrm{~kg} / \mathrm{m} 2$

Obese: $\mathrm{BMI}=30-34.9 \mathrm{~kg} / \mathrm{m} 2$

Severely obese: $\mathrm{BMI}=35 \mathrm{~kg} / \mathrm{m}^{2}$

For the study, obesity was defined as a BMI $>25 \mathrm{~kg} / \mathrm{m} 2$ which includes the overweight, obese and severely obese categories.

The male groups were less at risk with regard to weight. Seven out of every ten males had a normal weight. A point to note is the overweight category. Though the percentages are still low, the trend is that weight increases with age. Figure 1 depicts the female BMI cross-tabulated with the age groups. In the female group, obesity was prevalent in all the age groups, and the prevalence increased with age. Of concern is that $23.0 \%$ in the $35-40$ age group fall within the severely obese category.

\section{Waist-to-hip ratio}

The cut-off point for the waist-to-hip ratio is 1.0 for males or 0.85 for females (Department of Health, 2002). According to Figure 2, less than $1 \%$ of the males had a waist/hip ratio equal to or more than 1.0. This figure contrasts alarmingly with

$32.5 \%$ of females with a waist-to-hip ratio above the cut-off point. The percentage of females with a waist-hip ratio higher than the cut-off mark was prevalent in all age groups, and the prevalence increased with age.

\section{Hypertension}

According to World Health Organisation's International Society of Hypertension Guidelines for the management of hypertension (WHO, 1999), hypertension is defined as a blood pressure $=140 / 90$ $\mathrm{mmHg}$, or taking anti-hypertensive medication. In both sexes the prevalence of hypertension increased with age. The prevalence for the study sample $(n=604)$ was $15.8 \%$. However, hypertension was most prevalent in 35-40 age group in both sexes. In this age group, $36 \%$ of the males and $42.1 \%$ females were hypertensive.

Figure 3 reflects the compliance with hypertensive treatment and the degree of blood pressure control in the hypertensive respondents. The results indicate that 24 respondents with hypertension (25.3\%) were not being treated, and only $16(16.8 \%)$ had a desirable level of control with blood pressure under 140/90 $\mathrm{mmHg}$.

\section{Multiple risk factors of cardiovascular disease in the study sample}

Table 3 presents the prevalence of multiple risk factors of cardiovascular disease

\section{FIGURE 1: Female BMI cross-tabulated with age groups}

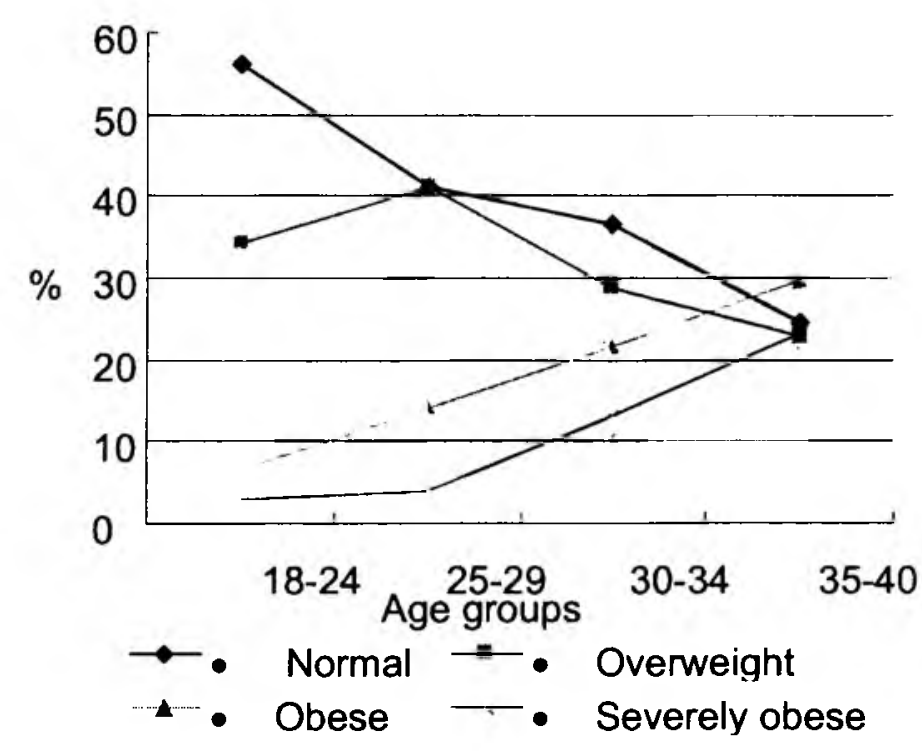




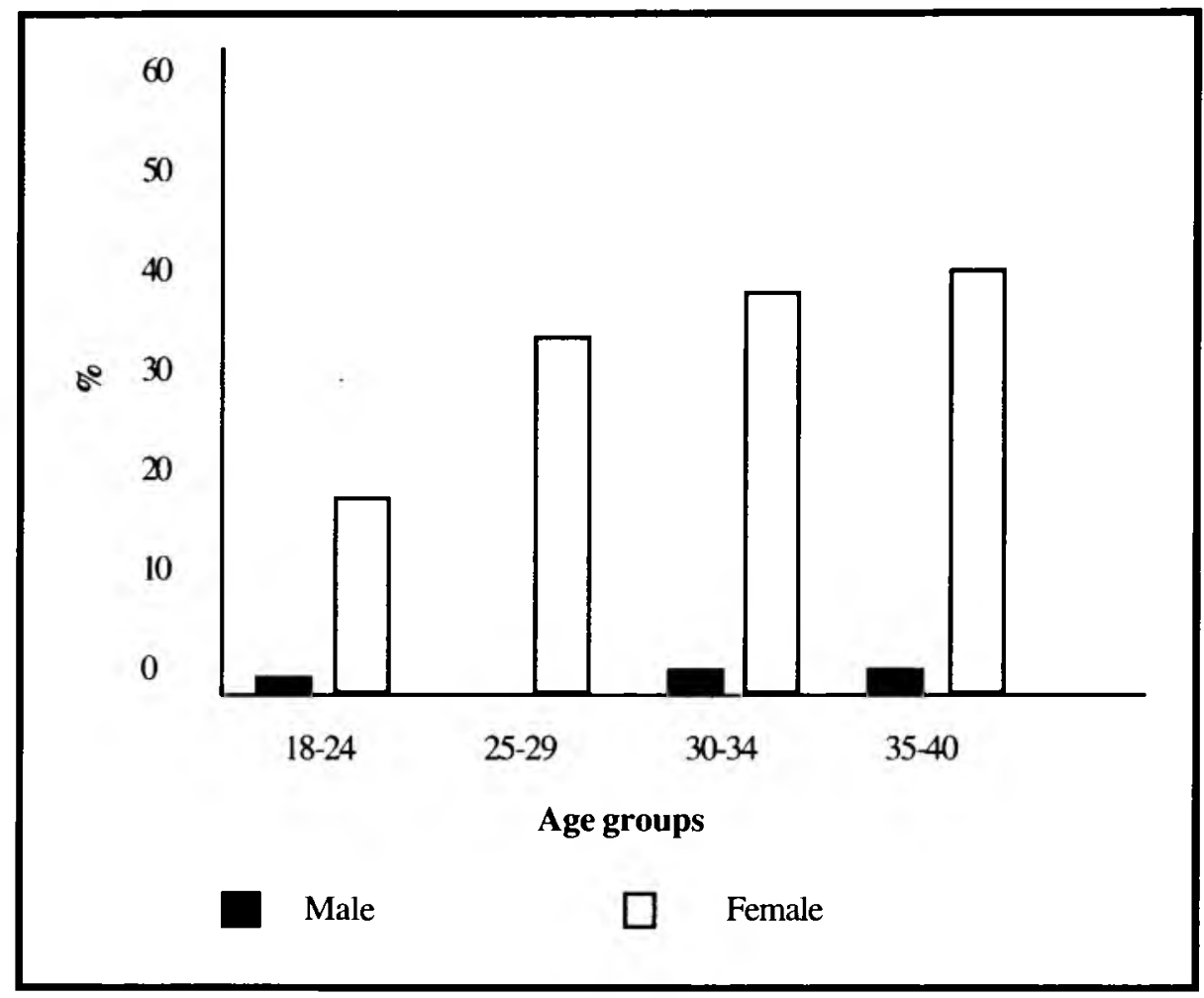

\section{FIGURE 3: Compliance with hypertensive treatment and degree of blood pressure control in the hypertensive respondents}

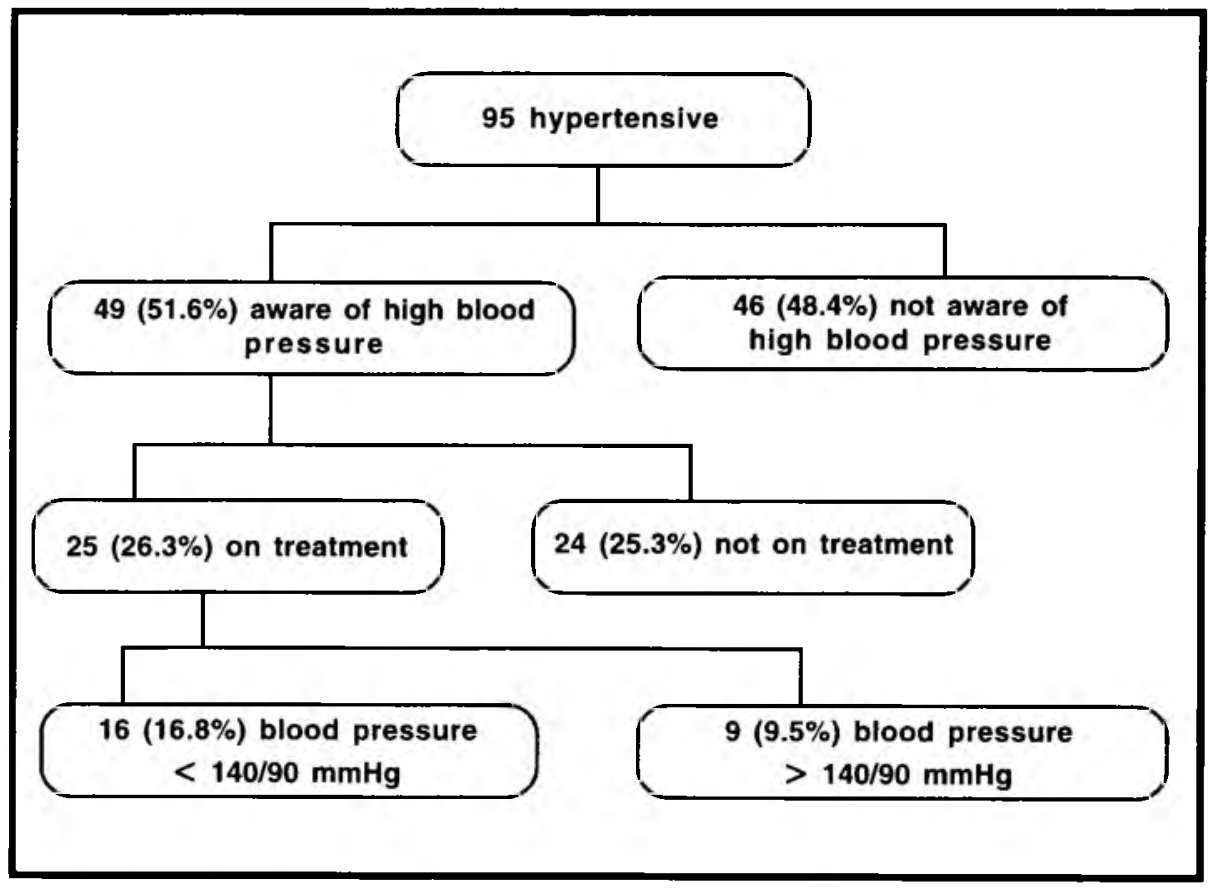

in the study sample. Only $8.8 \%$ of respondents had none of the six selected risk factors. Three out of every ten respondents $(32.3 \%)$ had three or more cardiovascular risk factors. The prevalence of three or more concurrent risk factors increased with age in both sexes. More than half $(50.5 \%)$ of the males had three or more of these risk factors in the 35-40 years age group. In addition, almost half $(43.8 \%)$ of the females in the $35-40$ age group had three or more of the risk factors.

\section{Discussion}

The study provides unique data on the prevalence of cardiovascular risk factors in a South African working-age population. The population was chosen from Zones 1, 2, 4 and 16 in the Ga-Rankuwa community. The results indicate that the risk factors are common in the study sample, but that different distributions of risk factors exist in the various age groups.

Seftel (quoted by Kruger, Venter \& Vorster, 2003:17) states that cardiovascular disease is still relatively uncommon in the black population of South Africa because the effects of risk factors are synergistic, rather than additive. South African black people do not get cardiovascular disease because they are physically active, have a low-fat diet and a favourable lipid profile. He argues that black males are extensively exposed to only one risk factor for cardiovascular disease, namely hypertension, while obesity and hypertension are common among black females. The current study confirms the arguments regarding hypertension in males and females, as well as obesity in the female group.

Smoking was reported quite frequently in the study sample, despite evidence that stopping smoking can be beneficial to people's health. Three times as many males were currently smoking as compared to females. Jajich, Ostfeld and Freedman (1984:2831) found that the higher risk of death from coronary artery disease among cigarette smokers was reduced to the same level as that of nonsmokers one to five years after cessation of smoking. The overall prevalence of cigarette smoking in the study $(21.9 \%)$ was similar to that found previously in South Africa (25\%) (Steyn et al., 2002:161). More males in the 18-24 age group were current smokers (39.3\%) when compared to other age groups. Steyn $e t$ al. (2002:170) stated that while the government has implemented strict control measures on advertising and smoking in public places, smoking was still reported quite frequently in males.

According to Pearson (1996:3023), consuming too much alcohol can raise the levels of triglycerides in the blood. It can also lead to hypertension, heart failure and an increased calorie intake. Consuming too many calories can lead to obesity and a higher risk of developing diabetes. Excessive drinking and binge drinking can lead to strokes. Other serious problems include foetal alcohol syndrome, cardiomyopathy, cardiac arrhythmia and sudden cardiac death. In the study sample, alcohol consumption was high in males $(17.7 \%)$ between the ages of 18 to 40 years, while only $3.7 \%$ of the 
females were using alcohol heavily.

Physical activity in black South African populations has not been studied extensively. In the study the males were more active than the females. Almost half of the female group (43.3\%) were categorised as inactive. It was also shown that the younger females were more inactive that the older groups. Television watching was the most prominent activity during leisure time. It is also known that $69.2 \%$ of the females were unemployed, which naturally precludes any work-related physical activity. Combined with $50 \%$ obesity from 35 years and older, the risk for cardiovascular disease and the resultant burden of disease for South Africa is high.

One of the important findings of this study is the inverse association between physical activity and cardiovascular risk factors, especially among females. The study also found that though some females were moderately active to active, obesity was still a problem. The active group had the highest mean values of body mass index and waist-to-hip ratio. The level of activity reported in the study needs to be investigated further to determine whether the measuring instrument should be refined or a different method of measuring should be used.

Taking into consideration that the 24hour recall method is known to underreport dietary intake, the mean intake of the study sample was less than the minimum dietary energy requirement of $7524 \mathrm{KJ}$ (Food and Agricultural Organisation, 1996). The dietary intake of the study sample reflects the typical black African diet, which conforms more closely to the prudent diet (Hunt, Gatenby \& Rayner, 1995:335) than the typical Western diet. The dietary intake of the study sample was high in carbohydrates and low in fat and fibre. A diet high in carbohydrates and low in fat and fibre could be associated with socioeconomic status. Families with limited income have to buy cheap foods which usually consist of carbohydrates.

The prevalence of obesity was high in the females in the study sample, especially in those aged 30 years and older. The prevalence of obesity was similar to other studies (Seedat et al., 1992:256; Mollentze et al., 1995:95). In addition, $32.5 \%$ of the females had a waist-to-hip ratio above the cut-off point of 0.85 . Less than $1 \%$ of the males had a waist-to-hip ratio equal to or more than 1.0 . The prevalence of a waist-to-hip ratio equal to or more than 1.0 in males was lower than the Medical Research Council (2004) ratio for black males. Bjorntor (1985:994) stated that an association between obesity and cardiovascular disease was found mainly in a subgroup of obese persons, that is a subgroup with central or android obesity. The mean waist-to-hip ratio of females for all age groups exceeded 0.8 , which is regarded as the cut-off value for increased risk of cardiovascular disease and death, independent of total body fat mass (Bjorntor, 1985:994). Other studies also indicated that indexes of abdominal adiposity, such as waist-to-hip and waist circumference, predict coronary heart disease and stroke more accurately than body mass index (Rexrode, Hennekens \& Willet, 1997:1539; Lakka, Lakka \& Tuomilehto, 2002:705).

Puoane et al. (2001:225) reported a confounding factor in relation to obesity. The authors reported that in some cultures, being overweight was associated with dignity, respect, confidence and good feeling about oneself. The possible reason is that respondents equated being underweight with being HIV positive. If a person perceived the threat that to lose weight may be associated with being HIV positive, it is difficult to adopt a healthier lifestyle in order to lose weight. Sengwana and Puoane (2004:69) also indicated that it is very difficult to encourage people to lose weight where being overweight is valued in a population. However, though difficult to achieve, studies have indicated that weight loss can lower blood pressure in hypertensive patients, as well as in normotensive persons (Georgiades et al., 2000:174).

The influence of a higher socio-economic status in relation to cardiovascular risk factors was also illustrated in the study. Respondents who lived in formal brick houses, were employed, and who had a higher level of education also exhibited a high risk level.

Hypertension is a major risk factor for cardiovascular disease. The study confirmed that hypertension in black people is common, and in both sexes the prevalence of hypertension increased with age. Hypertension was most prevalent in the $35-40$ age group, affecting $35.5 \%$ of males and $42.1 \%$ of females. More females than males were hypertensive in the corre- sponding age group in the study sample. The prevalence of hypertension in the selected population was $15.5 \%$ of males and $18.9 \%$ of females. The prevalence of hypertension in the Ga-Rankuwa community was similar to that found in the Mamre hypertension project (Metcalf etal., 1996:21).

Several important aspects regarding hypertension should be addressed in a follow-up intervention. These include:

- Having never checked their blood pressure, some respondents did not know that they were hypertensive.

- Although some of the respondents were already aware that they were hypertensive, they were not taking medication regularly. They have never been told that hypertension is called the "silent killer".

- The respondents' hypertension is not controlled even if the sufferers were taking medication.

- $\quad$ Some respondents only take medication when they feel ill.

- Higher levels of hypertension are associated with being employed.

Only $8.8 \%$ of the respondents did not exhibit any of the six selected risk factors. Almost a third of the respondents in this study had three or more risk factors for cardiovascular disease. These risk factors are known to act synergistically rather than additively (Kannel et al.,1986:825), which should engender increased concern over the results of the study.

\section{Recommendations}

The research study provided some answers on the prevalence of cardiovascular disease in Ga-Rankuwa, but also uncovered various areas where further research is essential. Recommendations for further research are presented:

- The risk factors for cardiovascular disease must be investigated in all age groups in Ga-Rankuwa.

- Dietary practices should be researched in depth to be able to develop community-specific interventions.

- Changes in lifestyle are important in the prevention of cardiovascular disease. There 
is limited information on physical activity in the community, and no evidence of attempts to improve physical i nactivity to prevent cardiovascular disease.

The health literacy of the community must determine as a basis for all future health promotion interventions.

\section{Conclusion}

Although reported cardiovascular disease is still uncommon, the risk factors for cardiovascular disease are prevalent in the Ga-Rankuwa community. Different distributions of risk factors exist in the various sex and age groups.

Epidemiological and community research over the past 30 years has shown in a convincing manner that cardiovascular disease is preventable, or at least its occurrence can be postponed (Winkleby et al., 1996:1773). These research observations have laid the foundation for a general scientific consensus that enough is known to take action on cardiovascular disease now, and that reducing risk levels is cost effective (Daviglus et al., 1998:1122). To reduce this risk, effective and practical programmes are needed.

One of the benefits of targeting cardiovascular disease as an entry point to issues of prevention and control of noncommunicable disease is that many of the risk factors associated with heart disease are also associated with other major chronic diseases such as cancer and diabetes mellitus. Therefore, an integrated approach to prevention will have a beneficial impact on many conditions (David \& MacLean, 1999:col.161). This finding again emphasises the importance of not developing health interventions with a single focus, for example hypertension or obesity. The risk factors are interwoven and affect each other. It is important to initiate an overall health project to lower the risk factors of cardiovascular disease in the Ga-Rankuwa community.

\section{References}

BJORNTOR, P 1985: Regional patterns of fat distribution. Annals Internal Medicine. 103(6), Dec.:994-5.

BRINK, HI 2002: Fundamentals of research methodology for health care professionals. Lansdowne: Juta.
BURNS, N \& GROVE, SK 1999: Understanding nursing research. Philadelphia: W. B Saunders.

BURNS, N \& GROVE, SK 2001: The practice of nursing research: conduct, critique, \& utilization. Philadelphia: WB Saunders.

DAVID, R, MACLEAN, MI) 1999: Cardiovascular disease: risk factors in older Canadians. Canadian Medical Association Journal. 161(8):S1

DAVIGLUS,MI,LIU, K, GREENLAND, P. DYER, AR, GARSIDE, DB, MANHEIM, L, LOWE, LP, RODIN, M, LUBITZ, J \& STAMLER, J 1998: Benefit of a favorable cardiovascular risk-factor profile in middle age with respect to Medicare costs. New England Journal of Medicine. 339(16), Oct.:1 122-1129.

DENOSA 1991: Ethical standards for nurse researchers, position paper. Pretoria: SANA.

DEPARTMENT of Health see SOUTH AFRICA. Department of Health.

FOOD AND AGRICULTURAL ORGANISATION 1996: The Sixth World Food Survey. Rome: FAO.

GEORGIADES, A, SHERWOOD, A, GULLETTE, ECD, BABYAK, MA, HINDERLITER, A, WAUGH, R, TWEEDY, D, CRAIGHEAD, L, BLOOMER, R \& BLUMENTHAL, JA 2000: Effects of exercise and weight loss on mental stress induced cardiovascular responses in individuals with high blood pressure. Hypertension. 36:171176.

HEIM, DL, HOLCOMB, CA \& LOUGHIN, TM 2000: Exercise mitigates the association of abdominal obesity with high-density lipoprotein cholesterol in premenopausal women: Results from the third National Health and Nutrition Examination Survey. Journal of American Diabetic Association. 100(11), Nov:: 1347-53.

HUNT, P, GATENBY,S \& RAYNER,M 1995: The format for the National Food Guide: performance and preference studies. Journal of Human Nutrition Dietetics. 8:335-351.

IGNATAVICIUS, DD, WORKMAN, ML \& MISHLER, MM 1999: $3^{\text {rd }}$ ed. Medical-Surgical Nursing across the Health
Care Continuum. Philadelphia: W.B. Saunders.

JAJICH,CL, OSTFELD, AM \& FREEMAN, DH 1984: Smoking and coronary heart disease mortality in the elderly. Journal of American Medical Association. 252(20):2831-2834.

KANNEL, WB, NEATON, JD, WENTWORTH, D, THOMAS, HE, STAMLER, J, HULLEY, SB. \& KJELSBERG MO 1986: Overall and coronary heart disease mortality rates in relation to major risk factors in 325,348 men screened for the MRFIT. American Heart Journal. 1 12(4):825-836.

KRUGER, HS, VENTER, CS \& STEYN, HS 2000: A physical activity questionnaire for a population in transition: the THUSA study. African Journal of Physical Health Education Recreation Dance. 6:54-64.

KRUGER, HS, VENTER, CS \& VORSTER, HH 2003: Physical inactivity as a risk factor for cardiovascular disease in communities undergoing rural to urban transition: the THUSA study. Cardiovascular Journal of South Africa. 14:16-23

KRUGER, HS, VENTER, CS \& VORSTER, HH 2001: Obesity in African women in the North West province, South Africa, is associated with an increased risk of non-communicable disease: the THUSA Study. British Journal of Nutrition, 86(66): 733-740.

LAKKA, HM, LAKKA, TA \& TUOMILEHTO, J 2002: Abdominal obesity is associated with increased risk of acute coronary events in men. European Heart Journal. 23(9), May:706-13.

LEVITT, NS, KATZENELLENBOGEN, JM, BRADSHAW, D, HOFFMAN, MN \& BONNICI, F 1993: The prevalence and identification of risk factors for NIDDM in urban Africans in Cape Town, South Africa. Diabetes Care, 16:601-607.

LUEPKER, RV,EVANS,A,MCKEIGUE, P \& REDDY, KS 2004: Cardiovascular Survey Methods. $3^{\text {rd }}$ ed. Geneva: World Health Organization.

MEDICAL Research Council see SOUTH AFRICA. Medical Research Council.

METCALF, CA, HOFFMAN, MN, 
STEYN,K,KATZENELLENBOGEN,JM \& FOURIE, JM 1996: Design and baseline characteristics of a hypertension intervention programme in a South African village. Journal of Human Hvpertension. 10(1), Jan.:21-26.

MOLLENTZE, WF, MOORE, AJ, STEYN, AF, JOUBERT, G, STEYN, K, OOSTHUIZEN, GM \& WEICH, DJV 1995: Coronary heart disease risk factors in a rural and urban Orange Free State black population. South Africa Medical Jounal, 85(2), Feb.:90-96.

OMAR, MA, SEEDAT, MA, MOTALA, AA \& BECKER, P 1993: The prevalence of diabetes mellitus and impaired glucose tolerance in a group of urban South African blacks. South African Medical Journal, 83(9), Sept.:641-643.

PEARSON, TA 1996: Alcohol and heart disease. Circulation. 94:3023-3025.

PUOANE, T, ROSLING, L, DE GOEDE, J \& VAN DER MEIJ, B 2001: Weightrelated beliefs and attitudes of obese urban women. Johannesburg: The $12^{\text {th }}$ congress of the Southern African Hypertension Society.

REXRODE, KM, HENNEKEN, S \& WILLET, WC 1997: A prospective study of body mass index, weight change, and risk of stroke in women. Journal of American Medical Association. 277:1539-1545.

SA see SOUTH AFRICA. Stats Council Census.

SEEDAT, YK, MAYET, FG, LATIFF, GH \& JOUBERT, G 1992: Risk factors and cardiovascular disease in Durban blacks - the missing links. South African Medical Joumal. 82(4), Oct.:251-256.

SENGWANA, MJ \& PUOANE, T 2004: Knowledge, beliefs and attitudes of community health workers about hypertension in the Cape Peninsula, South Africa. Curationis. 27(1), Mar.:65-71.

SMELTZER, SC \& BARE, BG 1996: Bruner and Suddart's Textbook of Medical-Surgical Nursing. $8^{\text {th }}$ ed. Philadelphia: Lippincott.

SOUTHAFRICA Department of Health 2002: South Africa Demographic and Health Survey 1998, Full Report. [Online]. Available from: http:// www doh.gov.za/ facts/1998/sadhs98/ [Accessed: 16/03/ 2005].
SOUTH AFRICA Medical Research Council 1987: Review of South African Mortality (1984) (Technical Report No. 1). Parow: Medical Research Council.

SOUTH AFRICA Medical Research Council 2004: Heart disease might no longer be the sole domain of the middleaged white male. MRC News. [Online], May. Available from: http:// www.mrc.ac.za/mrcnews/may2004/ heart.htm [Accessed: 18/08/2004].

SOUTHAFRICA Stats Council Census 2001: Census 2001 figures for GaRankuwa. [Online], March. Available from: http://www. statssa.gov.za/ extract.htm [Accessed: 18/03/2006].

STEYN, K 2006: Chronic diseases of lifestyle in South Africa: 1995-2005. Technical report. Cape Town: South African Medical Research Council. Available at: <http://www.mrc.ac.za/chronic/cdl 19952005.pdf > Accessed: 30/11/2006.

\section{STEYN, K, BRADSHOW,D, NORMAN,} R, LAUBSCHER, P \& SALOOJEE, Y 2002: Tobacco use in South Africans during 1998: The Demographic and Health Survey. Journal of Cardiovascular Risk. 9:161-170.

STEYN, K, FOURIE,J, ROSSOUW,JE, LANGENHOVEN,ML,JOUBERT, G \& CHALTON, DO 1998: Anthropometric profile of a black population of the Cape Peninsula in South Africa. East Africa Medical Journal, 75:35-40.

STEYN, NP, BURGER, S, MONYEKI, KD, ALBERTS, M \& NTHANGENI, G 2001: Seasonal variation in dietary intake of the adult population of Dikgale. South African Journal of Clinical Nutrition. 14:140-145.

THOROGOOD, M 2004: New research shows rural South Africa faces stroke crisis similar to affluent western countries. [Online]. Available from: http:// www. eurekalert.org/pub-releases/php [Accessed:05/02/2005].

WINKLEBY, MA, TAYLOR, CB, JATULIS, D \& FORTMANN, SP 1996: The long-term effects of a cardiovascular disease prevention trial: the Stanford Five-City Project. American Journal of Public Health, 86:1773-1778.

WRIGHT, SCD \& RAMUKUMBA, TS

2006: Life style risk factors in an urban
South African community: how to proceed? Unpublished article. Curationis.

WORLD HEALTH ORGANIZATION 1999: Guidelines for the management of hypertension. Geneva: World Health Organization. 